\title{
Contribución de los sitios web de la industria cinematográfica española a la percepción del Cine Español ${ }^{1}$
}

\section{Espainiako zinemagintzaren industriako webguneek espainiar zinemari buruzko iritziari egindako ekarpena}

\section{Contribution of Spanish cinematographic industry web sites to Spanish Cinema perception}

\author{
Jorge Clemente Mediavilla ${ }^{2}$ \\ Emilio C. García Fernández ${ }^{3}$
}

\section{zer}

Vol. 21 - Núm. 40

ISSN: $1137-1102$

e-ISSN: 1989-631X

DOI: $10.1387 /$ zer. 15513

pp. $67-83$

2016

Recibido el 4 de mayo de 2015, aceptado el 10 de diciembre de 2015.

\section{Resumen}

A partir de la contribución que realizan las páginas web relacionadas con el sector cinematográfico en España a la imagen que proyectan, se trata de valorar si existe una buena utilización de estos recursos online para mejorar la percepción del cine que se produce en el estado español, a través del análisis cualitativo de los sitios web más relevantes, que hiciera más completos los resultados obtenidos al aplicarse a la totalidad de sitios web seleccionados. Concluimos que existe poco o casi nulo interés por cuidar una imagen que pudiera hacer crecer el interés del público por la industria cinematográfica española.

Palabras clave: Cine español, internet, industria cinematográfica, web.

\section{Laburpena}

Espainiako zinemagintzaren sektoreko webguneek espainiar zinemaren inguruko iritziari egiten dioten ekarpena oinarri hartu da ikusteko ea behar bezala erabili diren sareko baliabide horiek herritarrek Espainiako estatuan ekoizten den zinemari buruz duten iritzia hobetzeko.

\footnotetext{
1 El presente trabajo es fruto del proyecto de investigación denominado "La imagen de marca del cine español”, financiado por el Ministerio de Economía y Competitividad (2011-2014).

2 Universidad Complutense de Madrid.jclemen@ucm.es

3 Universidad Complutense de Madrid.avia@ucm.es
} 
Horretarako, webgunerik garrantzitsuenen azterketa kualitatiboa egin da, hautatutako webgune guztien azterketarekin batera emaitza osoagoak lortu ahal izateko. Bada, ondorioztatu dugu ez dagoela interesik edo oso interes gutxi dagoela ikusleen artean Espainiako zinemagintzaren aldeko iritzia hobetu lezakeen irudia zaintzeko.

Gako-hitzak: Espainiar zinema, internet, zinemagintza, web.

\begin{abstract}
Using the contribution of web pages related to film industry in Spain in the image they project, with the purpose of eventually assessing whether there is an adequate usage of these online resources in order to improve the Spanish Cinema perception in Spain, across a qualitative analysis of the most relevant web sites, which was making the results more complete obtained on having be applied to the totality of selected web sites. We have come to the conclusion that there is hardly any interest, or virtually none, in watching over a image that may increase the public's interest in the Spanish film industry.
\end{abstract}

Keywords: Spanish cinema, internet, film industry, web. 


\section{Introducción}

La historia de la industria del cine español ha sido abordada especialmente a lo largo de los últimos cuarenta años desde perspectivas muy diversas, siendo la principal la evolución diacrónica y los estudios monográficos de aquellos profesionales implicados en el proceso de producción de la obra cinematográfica. Desde el punto de vista histórico, sin duda, son numerosos los trabajos que han buscado describir el paisaje sobre el que se ha desarrollado el cine español (García Fernández, 1985; VV.AA., 1995, 2010; Gubern, 1997), sus autonomías (García Fernández, 1985; Zunzunegui, 1985), ciudades y alguno de los períodos más relevantes (Heredero, 1993; García Fernández, 2002; Castro de Paz, 2002; Zunzunegui, 2005). También se ha profundizado en el análisis de sectores fundamentales de la creación cinematográfica como son los guionistas y productores (Riambau, Torreiro, 1998; 2008), en la aportación de profesionales de gran proyección en sus ámbitos y, por ende, del cine español (Hernández Les, 1986; Vidal, 1988; Sánchez Vidal, 1990) y en otros aspectos teóricos y analíticos que, en su conjunto, ofrecen una larga lista de textos surgidos desde la implantación de la democracia.

El mercado y la comercialización del producto cinematográfico español también han sido abordados fragmentariamente, siempre con el ánimo de apuntar momentos de gran proyección o situaciones críticas vividas (Cuevas, 1976, 1994; Pozo, 1984; Gómez Bermúdez de Castro, 1989; Álvarez Monzoncillo, 1993; Fernández Blanco, 1998; Alonso, 2003). No obstante, son escasas las aportaciones centradas en la imagen que ofrece el cine español tanto en su propio mercado como de cara al exterior. Los textos más próximos al tema habidos hasta la fecha -también escasos- se centran en la promoción y la publicidad que se hace del cine español, con el ánimo de establecer un punto de referencia entre la aceptación por parte del espectador español de su propio cine (Granados, 2004; Linares, 2008; García Fernández et al., 2012; García Fernández, Deltell, 2013; Deltell, García Fernández, 2014).

\section{Objetivos y método}

El presente estudio se propone comprobar si existen algunos pilares que permitan ofrecer una imagen positiva del denominado "cine español" en el contexto de internet, a través del estudio de los distintos lugares utilizados por los tres sectores afectados (producción, distribución, exhibición), organismos públicos y entidades de gestión de derechos, así como de las acciones llevadas a cabo en la red con el fin de atraer al público potencial al catálogo de películas españolas.

La hipótesis de partida se relaciona con el objetivo propuesto: cabría hablar de la imagen del cine español como resultado de un planteamiento no estratégico y arbitrario, derivado esencialmente de la propia valoración de la producción realizada, de su comparación con otras cinematografías y de los rasgos culturales del público español, lo cual influye notablemente en la recaudación en las salas de exhibición. En este sentido, la presencia del cine español en la red podría y debería favorecer una percepción positiva, que hasta el momento creemos que no ha sido explotada en su totalidad. En consecuencia, intentaremos validar si existe por parte de la industria cinematográfica española una conciencia de uso correcto de internet para vender 
mejor el producto cinematográfico o si, por el contrario, no existe tal concepto asentado en el sector.

Para llegar a esta meta, se hace necesario utilizar una metodología basada en el acercamiento a las páginas web de los distintos estamentos que conforman la industria cinematográfica en España, desde los subsectores de producción, distribución y exhibición, pasando por los organismos oficiales, entidades de gestión de derechos, así como los nuevos sitios dedicados al mercado digital en internet, sumando más de treinta sitios web relacionados con la industria cinematográfica española, que han sido analizados para averiguar si han desarrollado alguna estrategia común y cómo se ha afrontado, en su caso.

En ese sentido, y siguiendo a Díaz Soloaga, tradicionalmente se ha aceptado que las marcas son asimiladas y aceptadas por las personas durante un largo período de tiempo. De la misma manera, para realizar una modificación en una identidad de marca, no es suficiente con variar su aspecto externo ya que la mente tiende a quedarse largas temporadas con la misma imagen creada. Es necesario realizar un esfuerzo intensivo y duradero que manifieste la profundidad del cambio (Díaz Soloaga, 2002: 6).

Aunque aquí no estamos hablando de un producto comercial en concreto, consideramos muy claras las palabras de David Ogilvy cuando se reafirma en que cree "que cada anuncio debe ser considerado como una contribución al complejo símbolo que constituye la imagen de marca" (Bassat, 1999: 17), y buscando los puntos singulares que pudieran definir el denominado "cine español" podemos recoger lo que señalan Oliver y Alloza, cuando hablan de la promesa que los productores hacen al público y la experiencia vivida por éste, además de las relaciones de confianza que se establecen entre ambos y que dan origen a un conjunto de emociones entre un público heterogéneo (Oliver, Alloza, 2009: 135).

De un tiempo a esta parte, la entrada de internet en la vida de los ciudadanos ha removido los cimientos de una relación en la que una de las partes -en nuestro caso, los sectores industriales del cine español- se ha visto superada por la otra -el ciudadano, público, audiencia- pues lejos de sumirse en la pasividad más absoluta se ha transformado en un generador de opinión que puede dinamitar cualquier información que el primero genere (especialmente, si dicha información no atiende a los cánones de respeto y veracidad) y, mucho más, si el primero no ha hecho nada para divulgar adecuadamente los contenidos que son de interés o pueden ayudar en la difusión del producto; esto es, ya no resulta válida la capacidad de persuasión porque el receptor quiere un diálogo permanente, ya que se considera parte fundamental del espacio comunicativo (Martí, Muñoz, 2008: 156).

Siguiendo a Lee y Koubek (2010) y centrándonos en el objeto del presente estudio, hemos tenido en cuenta una serie de parámetros que permiten a un usuario valorar y recordar positivamente su paso por una web, con el fin de que ese "buen recuerdo" pueda asimilarse de alguna forma a una buena imagen del cine español; de este modo, los sitios web han sido analizados desde distintos puntos de vista, tales como la usabilidad, la presencia de marcas españolas reconocibles, la retroalimentación de las propias marcas, la actualización de contenidos, los enlaces a otras webs del sector, la legibilidad, etc.

Existen diversas opciones que sirven para valorar la eficiencia de un sitio web, entre otras las que señalan Cooke (2001), Timmons (1999) o Nielsen y Loranger 
(2006), que proponen tanto un análisis de los contenidos vertidos en ellas (acerca del grado de utilidad que poseen), como de navegación (organización, diseño, funcionamiento de los enlaces), experiencia del usuario (si merece la pena el tiempo invertido en la visita), multimedia (funcionamiento de las fotos, gráficos, audio y vídeo), tratamiento (contenidos inapropiados para determinadas edades) o acceso (velocidad de descarga, posicionamiento en los buscadores, etc.).

Por otra parte, otros autores como Tognazzini (2003) proponen unas pautas relacionadas con los conceptos de autonomía (el entorno del sitio debe ser abarcable y amigable), restricción de colores (los colores pueden ayudar a hacer más atractiva una web, pero si no son combinados de la manera correcta, el efecto puede ser el contrario), eficiencia del usuario (el sitio web debe ser productivo y de fácil manejo para los usuarios), minimización del tiempo de latencia (es necesario informar al usuario del tiempo que tardará en cargar la página), legibilidad (los colores de texto y fondo deben contrastar, así como la tipografía), búsquedas (un campo implementado en el propio sitio web con el fin de encontrar aquello que se requiere con mayor rapidez que mediante la propia navegación), contenido (redacción y ortografía deben cuidarse para no caer en una errónea apreciación por parte del usuario), funcionalidad (los enlaces deben estar operativos y llevar al lugar deseado).

En virtud de lo anterior, hemos optado por llevar a cabo un estudio cualitativo que incluyera las propuestas metodológicas mencionadas (mediante una completa ficha en la que se incluían todos los ítems), con el fin de abarcar un mayor espectro de análisis que hiciera más completos los resultados obtenidos al aplicarse a la totalidad de sitios web seleccionados. Dicha selección se realizó -en lo concerniente a los subsectores producción, distribución y exhibición- siguiendo la pauta de mayor relevancia en el subsector al que pertenecen, siendo el número de películas producidas, distribuidas y exhibidas en los últimos diez años el factor que ha permitido delimitar las cinco empresas productoras, distribuidoras y exhibidoras con mayores niveles de producción, distribución y exhibición, respectivamente. Este razonamiento creemos que es suficientemente válido, si seguimos a Dadek (1962) cuando realizaba una tipología de las empresas productoras cinematográficas basándose en el número de películas producidas frente al nivel de facturación y al número de empleados en plantilla, que en la mayoría de empresas pueden servir como criterio para realizar la diferenciación entre pequeñas, medianas y grandes empresas, pero no así en las dedicadas a la producción cinematográfica.

En el caso del resto de los sitios web propuestos para el análisis, no existen más páginas que las que hemos mostrado para cada uno de los apartados en que se divide nuestro estudio (organismos oficiales, entidades de gestión, sector digital), ya que su presencia en internet aún es incipiente ${ }^{4}$.

\section{Análisis}

A continuación vamos a mostrar un resumen ${ }^{5}$ de los resultados obtenidos a través del análisis de los sitios web de cada una de las entidades implicadas: Producción,

\footnotetext{
${ }^{4}$ No se han incluido los posibles sitios promocionales de las distintas webs por su carácter efímero, que podría distorsionar el análisis de las páginas web propuestas.

5 Debido a las limitaciones de extensión del artículo y la cantidad de sitios web seleccionados, se ha
} 
Distribución, Exhibición, Organismos oficiales, Entidades de Gestión y el que hemos denominado Sector Digital. En primer lugar, se trata de delimitar si estas páginas están configuradas correctamente siguiendo los ítems que hemos mencionado anteriormente, algo necesario para que resulten atractivas para el usuario, entendiendo que si este punto no se tiene en cuenta poco se puede hacer para que su percepción pueda ser positiva. Además, debemos constatar si concurre alguna zona común que nos ayude a comprender si hay motivos para pensar que existe un buen recuerdo de dichas páginas que pueda asimilarse de alguna forma a una buena imagen del Cine Español ${ }^{6}$.

\subsection{Sector Producción}

Actualmente, la Federación de Asociaciones de los Productores Audiovisuales de España (FAPAE) se configura como una Confederación de Federaciones y Asociaciones de Productores Audiovisuales, a través de una entidad sin ánimo de lucro que integra a la práctica totalidad de las empresas de producción de cine y televisión de España (cerca de 400 empresas productoras), que han ido asociándose tanto territorialmente como en función de la especialización y de las peculiaridades del sector.

Desde el punto de vista de la usabilidad, el sitio web de FAPAE cumple en la mayoría de los casos con lo aconsejable: el contenido es entendible y bien escrito, sin errores ni faltas ortográficas que lo desmerezcan; en cuanto a la legibilidad, el color del texto y el del fondo contrastan suficientemente ante el usuario, lo cual puede redundar en la facilidad a la hora de encontrar lo que se desea; respecto de la campo de "búsquedas", destinado a encontrar con rapidez en el propio sitio web, no constatamos su existencia, lo cual puede dificultar la navegación por la web. Por lo que respecta a la funcionalidad, parece lógico pensar que el enlace del Ministerio de Cultura debería llevarnos a la página de Cine y Audiovisuales del organismo, pero sin embargo aparece en su lugar la página de Industrias Culturales, mucho más amplia que la anterior y donde el usuario puede perderse con facilidad.

En cuanto a las zonas comunes con otras páginas web del mismo subsector de producción, al compararse con las cinco empresas productoras analizadas no encontramos ni un atisbo de similitudes con el sitio de FAPAE, ni respecto de la estructura, ni en los colores, ni siquiera en las imágenes de las películas que aparecen en ellos.

Por otro lado, se hace inevitable la comparación con su equivalente en los Estados Unidos de América -salvando las distancias-, Motion Picture Association of America (MPAA), si bien esta asociación agrupa, además de los grandes productores estadounidenses, a las empresas distribuidoras más relevantes, fundidas con las primeras en grandes grupos empresariales (majors). En la página principal, ocupando más de las dos terceras partes, se observa una franja en la que se muestran continua-

mostrado una información muy resumida de cada una de las páginas web analizadas, sin que ello signifique que dicho análisis no haya sido profundo y sistemático, siguiendo las pautas marcadas en la metodología citada.

${ }^{6}$ La realización del trabajo de campo se extendió a lo largo de los meses centrales de año 2014, por lo que a la fecha de publicación pueden existir variaciones respecto de la información que aquí se ha analizado. 
mente fotogramas de películas que se encuentran en cartelera: es decir, el producto, lo que se vende, se puede ver en primera línea y de un golpe de vista. Incluso el propio formato de la página, 16:9, se adapta a las nuevas pantallas de ordenadores que ya están en el mercado, desplazando a las de formato 4:3, algo que no ocurre con la página de FAPAE, que continúa apostando por ese formato 4:3, al igual que la inmensa mayoría de los sitios web analizados en este estudio. Además, la simplicidad del resto de la página es bien patente, con cuatro menús que nos llevan a las distintas partes del sitio web. En definitiva, una web mucho más simple y accesible donde el usuario se puede sentir cómodo y encontrar lo que busca con rapidez, con un campo de "búsquedas" por si se desea atajar en algún caso.

Para completar el análisis de este subsector se han seleccionado un total de cinco empresas productoras, las más relevantes de los últimos diez años (20042014) en cuanto al nivel de producción (número de películas producidas). Dos de ellas pertenecen a grupos de comunicación (Telecinco Cinema, Antena 3 Films), Castelao Pictures (Grupo Filmax) cuenta con una estructura de integración vertical (producción-distribución-exhibición), y dos son independientes (El Deseo, Tornasol Films).

La web de El Deseo posee una estructura clara, así como la venta de sus productos. En la zona de la izquierda, se puede observar toda la filmografía de la empresa y a la derecha se sitúa el acceso a las redes sociales y el cartel de su última producción. Respecto al encuentro de zonas comunes con otras páginas web del mismo subsector, no se produce más que en la zona de Enlaces, donde se puede acceder a los sitios web españoles de FAPAE, EGEDA y la Academia de Cinematografía. Por otro lado, no se observan enlaces directos a otras páginas en la web inicial.

La estructura de la web de Tornasol Films es sencilla, clara y permite al usuario encontrar fácilmente lo que desea. En cuanto a las zonas comunes con otras páginas web del mismo subsector, no existe relación alguna en parte alguna del sitio web.

Telecinco Cinema, al pertenecer a un grupo de comunicación, tiene una imagen de marca mucho más presente que en los casos anteriores, siguiendo fielmente el libro de estilo marcado por la empresa matriz, aunque su estructura es más compleja. Los enlaces a los distintos canales de televisión del grupo son bien visibles y reconocibles al usuario, y no existen vínculos a otras empresas que no formen parte del grupo Mediaset.

Atresmedia Cine forma parte del grupo Atresmedia Corporación (Antena 3 TV), siendo anteriormente denominada Antena 3 Films y también Ensueño Films. Como en el caso anterior, al pertenecer a un grupo de comunicación, se respeta el libro de estilo de la matriz quedando poco resquicio a la improvisación. La estructura es más compleja que en el caso de las productoras independientes y se incluyen báneres publicitarios ajenos al propio sector audiovisual. No existe correspondencia con otras empresas productoras ni enlaces con organismos ni instituciones relacionadas.

Castelao Pictures forma parte del grupo Filmax, que nació con vocación de empresa importadora y distribuidora de productos cinematográficos en nuestro país. No tiene página web propia, sino que es la propia de Filmax la que absorbe todo el protagonismo, con una sección Películas donde se puede encontrar el catálogo de las producciones de la empresa. 


\subsection{Sector Distribución}

La Federación de Distribuidores Cinematográficos deja bastante que desear respecto de la usabilidad de su sitio web, con enlaces que no se han actualizado desde hace tiempo y que no dirigen a web alguna. En cuanto a los lugares comunes de la web, podemos observar que en el propio logotipo de la federación se utilizan los colores de la bandera española, algo que sin duda puede ayudar a recordar la "Marca España". Además, en su apartado de Enlaces se pueden encontrar muchas páginas relacionadas con el sector que no se pueden localizar en el resto de las páginas analizadas: desde las comisiones fílmicas hasta las entidades de gestión de derechos audiovisuales.

Las empresas distribuidoras españolas que han sido objeto de análisis son las más importantes de nuestro país en los últimos diez años (2004-2014): eOne (anteriormente Aurum), Filmax, Golem, Lauren, Altafilms (recientemente desaparecida). Lauren y Altafilms son las que tienen una imagen más tradicional, menos adecuada a los gustos del usuario, mientras que las otras tres empresas se asemejan mucho a lo que hacen los distribuidores estadounidenses, con imágenes grandes y de alta resolución, que permiten atraer al espectador en cuanto se conecta a la web.

Respecto de los lugares comunes, no existen menús dedicados a Enlaces con otras páginas del sector, así como tampoco podemos encontrar colores, logotipos o cualquier otro elemento que pudiera relacionarse con la "Marca España".

\subsection{Sector Exhibición}

La Federación de Entidades de Empresarios de Cine de España (FECE) posee una web en la que, respecto de la usabilidad, casi todos los enlaces funcionan perfectamente y la navegación a través de sus menús es sencilla. El diseño de la página ha quedado algo anticuado, sin ocuparse demasiado de su actualización con el paso de los años, algo que podemos considerar negativo, si tenemos en cuenta que los usuarios van cambiando la forma de acercarse a las páginas web según avanzan en su uso.

No existen lugares comunes de la web que nos remitan a otras páginas relacionadas con el sector. Tampoco se hace referencia a otros organismos ni a los sitios de los propios socios. Hay que reseñar que no funciona el enlace en el que se debía visualizar el mapa de socios y su composición, lo cual produce confusión al no poder acceder a una información que se puede considerar como necesaria para la comprensión de quiénes componen dicha federación.

Las empresas exhibidoras españolas que han sido objeto de análisis son las más importantes de nuestro país en los últimos diez años (2004-2014): Cinesa, Yelmo, Abaco-Cinebox, ACEC (Asociación Catalana de Empresas Cinematográficas), y UCC (Unión Cine Ciudad). Al tratarse del último eslabón de la cadena, el más cercano al público, y ostentar el privilegio de recaudar el dinero de las entradas que pagan los espectadores, el sentido del negocio está totalmente claro en sus páginas web, que venden el producto desde la página de inicio, sin ambages y de un modo quizá poco estético. En ese sentido, el hay que tener en cuenta que el usuario de estás páginas lo que realmente desea es encontrar la sala y la película deseada, de forma rápida y con la posibilidad de comprar la entrada en ese mismo momento. 
Sin duda, la que posee una web más adecuada y al mismo tiempo elegante es Yelmo, con una estética que recoge la herencia del mundo hollywoodiense. El resto adolece de esa imagen atractiva y se limita a enseñar de una forma más o menos abigarrada los productos que se pueden adquirir. Del mismo modo, la única que posee campo de "búsquedas" es la web de Yelmo, lo cual vuelve a hablar bien de ella.

Respecto de los lugares comunes, no existen menús dedicados a Enlaces con otras páginas del sector, así como tampoco podemos encontrar colores, logotipos o cualquier otro elemento que pudiera relacionarse con la "Marca España".

En cuanto al contacto con las redes sociales, todas excepto ACEC poseen enlaces a Facebook, YouTube o Twitter. Además, todos los enlaces funcionan correctamente y las páginas se actualizan muy a menudo, debido precisamente al tipo de producto que se vende, películas, que semanalmente van rotando en la cartelera.

\subsection{Sector Digital}

Respecto a la imagen de este sector en internet, al no tener ataduras y costumbres heredadas, ya que se ha concebido dentro de la propia red desde su nacimiento, parte de cero y ello debería redundar en una visión del problema mucho más acertada. En ese sentido, no queremos dejar de lado la aparición y posterior consolidación de los videoclubes españoles en internet, como nueva plataforma de difusión de películas nacionales. Recientemente han ido apareciendo empresas dedicadas al visionado online de películas, que poco a poco van consolidándose en el mercado audiovisual español. Entre las más relevantes se encuentran 400 films, ADN Stream, Cineclick, Filmin, Filmotech, Márgenes, Mubi, Nubeox, Plat, Voddler, Wuaki, Yomvi y Youzee agrupadas en el portal "Me siento de cine", que apuesta por la oferta legal de cine en internet.

De todas ellas sólo dos difunden exclusivamente cine español: Filmotech y Márgenes. Filmotech es el videoclub online de EGEDA, la entidad de gestión de los productores audiovisuales españoles. Si bien tiene una estructura sencilla y una buena legibilidad, no se visualizan enlaces a otras webs del sector (productores, distribuidores exhibidores, ICAA, etc.), distintas de otros videoclubes legales online que sí recomiendan. No existen, por tanto, elementos que puedan plantear relación alguna con la marca "Cine Español".

De otra parte, Márgenes es un espacio que ofrece la posibilidad de acceder a películas españolas surgidas en lo que ellos mismo denominan "la periferia de la industria cinematográfica convencional" o de marcado carácter autoral. Se trata, por tanto, de un videoclub de carácter alternativo que intenta dar salida a aquellas obras que no han tenido un camino sencillo en el circuito comercial habitual. La página está subvencionada por el ICAA, pero no existe un enlace que lleve a la web ministerial. Tiene una estructura sencilla y una buena legibilidad; además, todos los enlaces funcionan correctamente y los contenidos son renovados con frecuencia, lo cual indica una constante actualización.

La Federación para la Protección de la Propiedad Intelectual (FAP) tiene una web dedicada a fomentar las actuaciones legales en el sector audiovisual y de entretenimiento (videojuegos) y, por tanto, se favorece la presencia de enlaces a otras páginas relacionadas con la protección de los derechos de propiedad intelectual del sector, 
incidiendo en la concienciación ciudadana sobre el respeto de dichos derechos y declarando la guerra a la piratería. El sitio web de FAP es accesible, desde el punto de vista de la usabilidad, con un contenido bien escrito, sin errores ni faltas ortográficas; en cuanto a la legibilidad, el fondo y el texto contrastan perfectamente ante el usuario, lo cual redunda en la sencillez a la hora de acceder a lo que se busca; respecto del campo de "búsquedas", destinado a encontrar contenidos rápidamente en el propio sitio web, no constatamos su existencia, lo cual puede dificultar la navegación por la web. Por lo que respecta a la funcionalidad, existe algún enlace que no funciona correctamente, como por ejemplo la descarga de manuales o guías de formación para padres respecto del buen uso de las tecnologías digitales. En cuanto al diseño, podemos considerarlo como excesivamente sobrio, lo cual puede transmitir al usuario una sensación de web poco trabajada en ese sentido, aunque cumple con la función de mostrar los enlaces disponibles relacionados con las acciones antipiratería. Quizá se echa en falta algún enlace a otros sitios que también luchan en el mismo sentido, como EGEDA o el propio ICAA.

\subsection{Organismos Oficiales}

El sitio web del ICAA contiene una gran cantidad de información, lo que debería suponer una estructura clara para una adecuada navegación que haga sentirse cómodo al usuario. No obstante, al igual que la mayoría de las paginas ministeriales, nos encontramos con una navegación difícil, ya que aunque el contenido está bien escrito (se trata de una página del Gobierno de España) se hace onerosa su navegación; el color del texto y el del fondo contrastan suficientemente ante el usuario, pero el tamaño de la letra es pequeño y con un interlineado excesivamente estrecho, lo cual hace que su lectura sea dificultosa y por tanto la navegación no sea óptima. Por lo que respecta a la funcionalidad, todos los enlaces funcionan correctamente, sin excepciones; eso sí, desde las páginas hijas no se puede volver a la página de inicio, algo que no se comprende en el año 2014: al pulsar el icono del ICAA no ocurre nada en absoluto. En cuanto al diseño, debería mejorarse dado que no ha variado desde hace muchos años y ha quedado desfasado, con excesivo texto en cada una de las páginas y poca visibilidad, aunque cumple con la función de mostrar la información que se requiere. En este sentido debemos decir que no existen enlaces a las diferentes consejerías relacionadas con la cinematografía, ni con las entidades (federaciones, asociaciones, entidades de gestión, etc.) del sector cinematográfico español y, lo que es más sorprendente, tampoco encontramos enlace alguno a la web de la Marca España. Aquí podemos observar la falta de coordinación entre unas instituciones que forman parte del mismo gobierno y que deben estar relacionadas intrínsecamente. Si se desea promover la Marca España es necesario que desde las propias instituciones oficiales se predique con el ejemplo, fomentando la retroalimentación de la información.

Respecto de las diversas Comunidades Autónomas del país, no existen páginas específicas dedicadas al sector cinematográfico, por lo que no es posible llevar a cabo el análisis de sus webs.

En cuanto al Instituto Cervantes, traemos aquí su web porque es la única de todas las páginas analizadas que muestra un enlace con la web dedicada a la Marca España, lo cual parece obvio aunque hasta este momento no había ocurrido todavía. 
En la pestaña dedicada a la Cultura pueden encontrarse actividades relacionadas con la difusión de la lengua española a través del cine español. Es la única ligazón con el sector cinematográfico de esta web, además de la ya citada con la Marca España.

Marca España se define como una política de Estado, cuya eficacia reside en el largo plazo. La garantía de la continuidad de este proyecto es que se desarrolle fruto del consenso, por encima de cambios políticos. Su objetivo principal es mejorar la imagen de España, dentro y fuera del territorio nacional. El Alto Comisionado Marca España depende orgánicamente del Ministro de Asuntos Exteriores y Cooperación. En la pestaña dedicada a Educación, Cultura y Sociedad se encuentra el menú dedicado a Cine y Artes Escénicas, donde tiene cabida la información relacionada con el sector cinematográfico. Si bien la navegación es sencilla y los enlaces funcionan correctamente, se echa en falta unos contenidos más amplios; si se pretende reducir la Marca España Cine a Pedro Almodóvar o Antonio Banderas se está haciendo un flaco favor a la cinematografía estatal. Obviamente, las sombras del director manchego y del actor malagueño son muy grandes, pero ello no ha de ocultar las del resto del sector.

A favor de la web hay que resaltar los colores que predominan en ella, que recuerdan constantemente que estamos ante una página que quiere representar los intereses españoles. Sin embargo, no existen enlaces a los distintos subsectores de la industria cinematográfica, ni a la propia web del ICAA, como se dijo ya anteriormente. Ello no hace más que confirmar la inexistencia de un planteamiento serio y a gran escala para conocer y promocionar la imagen de marca del cine español. No se piensa en común, no hay coordinación entre los distintos estamentos que conforman el sistema económico cinematográfico. La propia Administración, que podría liderar esa coordinación, obra de forma que, a la vista de lo que podemos observar en sus páginas web, deja mucho que desear.

En definitiva, la web parece que no llega a su destino; en la era digital, donde internet es el rey, todos los medios que se usan en la red deben ser explotados de la mejor manera posible, de modo que parecería normal que existieran enlaces en las principales redes sociales donde se estuviera fomentando día y noche la imagen que se quiere proyectar (sólo un pequeño icono en la parte superior, casi desapercibido, nos invita a introducirnos en el mundo de Twitter). En particular, la web no dedica suficiente espacio al cine español, espacio además que debe ser compartido con las Artes Escénicas, restando aún más protagonismo; mientras, la Gastronomía y los Deportes gozan de sus propios espacios individualizados.

\subsection{Entidades de Gestión}

La web de la Entidad de Gestión de Derechos de los Productores Españoles (EGEDA) acaba de renovarse tras muchos años de espera, actualizando su imagen y con una legibilidad mucho mayor. Los fondos blancos permiten que los textos se lean correctamente, aunque quizás exista un exceso de los mismos mientras escasean las imágenes.

En cuanto a los lugares comunes de la web, se puede ver con claridad que, una vez más, no se guarda relación con el resto de agentes implicados en el sector, ya que sólo se enlaza con los propios socios de la entidad. A pesar de ser una entidad tutelada por el Ministerio de Educación, Cultura y Deporte no encontramos enlaces que les 
relacionen con el gobierno de España, ni tampoco con la Confederación que agrupa a sus propios socios, los productores cinematográficos (FAPAE). De hecho no existe un apartado de Enlaces como tal, ni existe un campo para "búsquedas" internas de la web, lo cual obliga al usuario a navegar hasta que encuentra lo que busca.

Por otro lado, la Sociedad de Gestión de Autores y Editores (SGAE) posee una página web con predominancia del color rojo, algo que podría recordar en cierto modo a la Marca España, pero no parece que sea ese el motivo de tal elección, ya que posteriormente se observa que no existe tal relación. La web no parece demasiado adecuada ni fácilmente usable, entre otras cosas porque al pulsar sobre los menús de cabecera, la página cambia su configuración, creando en el usuario una sensación de despiste continuado. No es fácil la navegación hasta llegar a la pestaña dedicada a la Formación (de hecho la encontramos con suerte), donde se puede acceder a información relacionada con música, cine y artes escénicas. Dentro del apartado dedicado al Cine se encuentran diversos certámenes, concursos y muestras dedicadas a la difusión de obras españolas. Sin embargo, no existe relación con la industria cinematográfica que provee a esta entidad de ingresos por recaudación de obras cinematográficas, ni tampoco con el ICAA, ni con Marca España.

Por otro lado, las sociedades de gestión AISGE (Artistas e Intérpretes Sociedad de Gestión) y AIE (Artistas, Intérpretes y Ejecutantes) no son demasiado relevantes en este sentido y sus páginas web no revelan utilidad más que para sus socios, por lo que no debemos incluirlas en nuestro estudio.

En cuanto a la web de la Academia de las Artes y las Ciencias Cinematográficas de España, desde el punto de vista de la usabilidad cumple bien con lo recomendable en este sentido, con unos contenidos comprensibles y redactados con corrección; en cuanto a la legibilidad, la imagen de la página es limpia y el color del texto y el del fondo contrastan mucho, algo que facilita la lectura de los contenidos; por contra, no existe un campo de "búsquedas", donde se pueda encontrar contenidos en la propia web, algo que, sin duda, puede resultar no grato para quien acceda a la navegación por la página. En cuanto a la funcionalidad, debería existir un enlace al ICAA, como órgano oficial relacionado con la cinematografía patria, pero no se da tal circunstancia. Sin embargo sí tiene presencia en algunas de las redes sociales más importantes (YouTube, Twitter, Facebook).

En cuanto a las zonas comunes con otras páginas web, no podemos constatar su existencia, lo cual nos lleva a pensar - una vez más- en la falta de coordinación entre todos los intervinientes de la industria cinematográfica del estado español.

A modo de ejemplo, si comparamos esta web con su homóloga en los Estados Unidos de América (Academy of Motion Picture Arts and Sciences), podemos encontrar algunas diferencias al respecto. En la página principal se observa una fotografía con un tamaño que ocupa casi tres cuartas partes de la pantalla, en la que se van mostrando diferentes fotografías con los distintos ítems a promocionar en ese momento oportuno. Obviamente, la actualización es permanente y las fotografías van cambiando dependiendo de la propia vigencia de cada una de ellas. Al igual que ocurría con la MPAA, lo que se desea vender es ubicado en posición absolutamente preferente, coincidiendo ambas en los colores corporativos de sus respectivos sitios web (fondo negro, textos blancos y dorados). Además, la simplicidad del resto de la página es casi insultante, con distintos menús que nos permiten llegar a las diferentes 
partes de la página. Se trata de una web mucho más simple, accesible y funcional donde el usuario se encuentra cómodo buscando lo que desea, y con un campo de "búsquedas" para ganar tiempo, si es necesario.

\section{Discusión}

Los resultados que arroja el estudio de las páginas web analizadas ${ }^{7}$ nos confirman, por un lado, que los responsables de dichas páginas no tienen demasiado en cuenta los ítems propuestos en la metodología utilizada, a la hora de diseñar sus sitios web, lo cual puede influir sobremanera en la percepción que tiene el visitante de dichas páginas sobre aquello que supuestamente se intenta "vender": cine español.

Las webs relacionadas con el cine español deben sufrir modificaciones importantes tanto en su estructura como en la propia imagen que proyectan, modernizándose y adaptándose a lo que el usuario espera encontrar, pues de otro modo no cumplirán con su misión, cayendo en el olvido poco a poco sin posibilidad de retorno. El acceso a los contenidos, así como la eficiencia del usuario y su autonomía en la navegación, la restricción de los colores utilizados, la minimización del tiempo de latencia, la legibilidad, las búsquedas internas o la funcionalidad de las páginas analizadas, tal y como hemos comprobado, no tienen una repercusión válida en la interacción del usuario con ellas.

Se hace necesaria la actualización permanente de la información contenida en los sitios web, así como un cambio radical en la propia forma de estructurar y mostrar la información que debe llegar a los usuarios, utilizando para ello herramientas actualizadas de gestión de páginas web (Dreamweaver, Incomedia Website, Avanquest WebEasy, Magix Web, etc.), ya que no es posible olvidar la evolución del software de creación de páginas web a la hora de plantear la actualización de los sitios en internet.

Respecto a la presencia de una imagen española reconocible, así como la retroalimentación de la misma y la actualización de contenidos de dichas páginas web, debemos aceptar como válido que, salvo excepciones muy contadas, tampoco se ha cuidado este aspecto en demasía, ya que la mayoría de ellas no atiende la actualización de los contenidos, encontrándonos con un panorama desolador algunas veces, ya que los textos pueden llegar a estar inactivos demasiado tiempo, con el perjuicio y la insatisfacción del usuario que intenta encontrar información navegando entre ellos.

Creemos que, más que deseable, sería conveniente para la reafirmación de una mejor percepción del cine español que los diferentes estamentos pusieran de su parte para homogeneizar y de alguna manera entrelazar sus propios intereses, a través de la intercomunicación de sus diferentes sitios web y de la semejanza de ciertas partes de sus páginas, intentando de ese modo que el usuario capte que se encuentra ante una misma industria, un único sector con muchos agentes implicados.

Las conclusiones preliminares del estudio indican el casi nulo interés que han demostrado los sectores implicados en la existencia de una buena percepción del cine español en internet. El análisis de las páginas web de los distintos estamentos

\footnotetext{
7 Hay que tener en cuenta que el análisis de los sitios web ha sido llevado a cabo en el año 2014, mientras que la publicación del artículo se fecha en 2016, lo cual puede explicar que ciertas constataciones que aquí se detallan, así como las imágenes que aquí se muestran hayan podido sufrir variaciones al evolucionar las propias páginas web objeto de nuestro estudio.
} 
involucrados así lo confirma. No existe una política común porque no hay un tejido común ni unos intereses comunes, sino más bien un conglomerado de organismos, asociaciones y empresas que intentan hacer "su cine", olvidando que la unión de todos ellos probablemente tendría unos resultados mucho más beneficiosos para la industria cinematográfica a la que pertenecen.

\section{Referencias bibliográficas}

ALLOZA, Ángel (2001). La gestión estratégica de la marca. En VILLAFAÑE, Justo. El estado de la publicidad y el corporate en España y Latinoamérica. Madrid: Ediciones Pirámide.

ALONSO, Luis (2003). Once miradas sobre la crisis y el cine español. Madrid: Ocho y Medio.

ÁLVAREZ MONZONCILLO, José María (dir.) (1993). La industria cinematográfica en España (1980-1991). Madrid: Ministerio de Cultura/Fundesco.

BASSAT, Lluis (1999). El libro rojo de las marcas. Madrid: Espasa Calpe.

CASTRO DE PAZ, José Luis (2002). Un cinema herido. Los turbios años cuarenta en el cine español (1939-1950). Barcelona: Paidós.

COOKE, Alison (2001). A guide to finding quality information on the Internet: selection and evaluation strategies. Londres: Library Association Publishing.

CUEVAS, Antonio (1994). Las relaciones entre el cinema y la televisión en España y otros países de Europa. Madrid: EGEDA/Comunidad de Madrid.

CUEVAS, Antonio (1976). Economía cinematográfica. La producción y el comercio de películas. Madrid: Edición del Autor [Madrid: Imaginógrafo. 1999].

DADEK, Walter (1962). Economía cinematográfica. Madrid: Rialp.

DELTELL, Luis; GARCÍA FERNÁNDEZ, Emilio Carlos (2014). El cine español en Twitter. Creación de líderes de opinión, promoción cinematográfica y desarrollo de marca. Comunicación presentada en el IV Congreso Internacional de la AE-IC "Komunikazio Eremuak/Espacios de Comunicación". Bilbao.

DELTELL, Luis y GARCÍA FERNÁNDEZ, Emilio Carlos (2014). ¿Y si desaparecen las salas de cine? La promoción y exhibición del cine español en la era digital. En GONZÁLVEZ VALLÉS, Juan Enrique (coord.). Redes sociales y lo 2.0 y 3.0. Madrid: Visión Libros.

DÍAZ SOLOAGA, Paloma (2002). Construcción de la imagen de marca en internet. En: Área Abierta, n ${ }^{\circ}$, p. 6.

FERNÁNDEZ BLANCO, Vicente (1998). El cine y su público en España. Un análisis económico. Madrid: Fundación Autor.

GARCÍA FERNÁNDEZ, Emilio Carlos (1985). Historia del cine en Galicia. 18961984. La Coruña: La Voz de Galicia.

GARCÍA FERNÁNDEZ, Emilio Carlos (1995). Historia ilustrada del cine español. Madrid-Barcelona: Planeta.

GARCÍA FERNÁNDEZ, Emilio Carlos (2002). El cine español entre 1896-1939. Historia, industria, filmografía y documentos. Barcelona: Ariel. 
GARCÍA FERNÁNDEZ, Emilio Carlos (2013). Consolidar la imagen a través de la comunicación. En: Academia. Revista del Cine Español, $\mathrm{n}^{\circ} 201$.

GARCÍA FERNÁNDEZ, Emilio Carlos et al. (2012). El cine español, ese gran desconocido. Un acercamiento desde la mirada del espectador para definir su marca. En VISA, M.; VARGAS, J.J. (coords.): El I+D+i y el EEES. Madrid: Visión Libros.

GARCÍA FERNÁNDEZ, Emilio Carlos; DELTELL, Luis (2013). La promoción fílmica en el universo digital. Hacia el ocaso de la exhibición cinematográfica en España. En: Historia y Comunicación Social, vol. 18, $\mathrm{n}^{\circ}$ especial.

GÓMEZ BERMÚDEZ DE CASTRO, Ramiro (1989). La producción cinematográfica española. De la transición a la democracia (1976-1986). Bilbao: Mensajero.

GRANADOS, Ruth (2004). La comunicación cinematográfica por Internet en Espa$\tilde{n} a$. Madrid: Universidad Complutense (Tesis inédita).

GUBERN, Roman (coord.) (1997). Un siglo de cine español. Madrid: Academia de las Artes y las Ciencias Cinematográficas de España.

FERNÁNDEZ HEREDERO, Carlos (1993). Las huellas del tiempo. Cine español 1951-1961. Valencia/Madrid: IVAC/Filmoteca Española.

HERNÁNDEZ LES, Juan Antonio (1986). El cine de Elías Querejeta, un productor singular. Bilbao: Mensajero.

LINARES, Rafael (2008). El uso del marketing cinematográfico en la industria del cine español. Móstoles: Universidad Rey Juan Carlos (Tesis inédita).

MARTÍ, José; MUÑOZ, Pablo (2008). Engagement Marketing. Una nueva publicidad para un marketing de compromiso. Madrid: Pearson Educación.

NIELSEN, Jakob; LORANGER, Hoa (2006). Usabilidad. Prioridad en el diseño Web. Madrid: Anaya Multimedia.

OLIVER, Xavier; ALLOZA, Ángel (2009). Atrapados por el consumo. Madrid. LID Editorial Empresarial.

POZO, Santiago (1984). La industria del cine en España. Legislación y aspectos económicos (1986-1970). Barcelona: Universidad de Barcelona.

RIAMBAU, Esteve; TORREIRO, Casimiro (1998). Guionistas en el cine español. Quimeras, picarescas y pluriempleo. Madrid: Cátedra/Filmoteca Española.

RIAMBAU, Esteve; TORREIRO, Casimiro (2008). Productores en el cine español. Estado, dependencias y mercado. Madrid: Cátedra/Filmoteca Española.

SÁNCHEZ VIDAL, Agustín (1990). Borau. Zaragoza: Caja de Ahorros de la Inmaculada de Aragón.

LEE, Sanwong; KOUBEK, Richard (2010). The effects of usability and web design attributes on user preference for e-commerce web sites. En: Computers in Industry, vol. 61, no 4 .

TIMMONS, Jeffry (1999). New Venture Creation: Entrepreneurship for the 21st Century, Nueva York: Irwin McGraw Hill.

TOGNAZZINI, Bruno (2003). "First principles of interaction design". En AskTog Interaction Design solutions for the real world. [http://www.asktog.com/basics/ firstPrinciples.html]. Consultado el 28 de agosto de 2014.

VIDAL, Nuria (1988). El cine de Pedro Almodóvar. Madrid: ICAA/Ministerio de Cultura. [Barcelona: Destino. 1989].

VV.AA. (1995). Historia del cine español. Madrid: Cátedra. 
ZUNZUNEGUI, Santos (2005). Los felices sesenta. Aventuras y desventuras del cine español (1959-1971). Barcelona: Paidós.

ZUNZUNEGUI, Santos (1985). El cine en el País Vasco. Bilbao: Diputación Foral de Vizcaya.

\section{Sitios Web}

Ábaco Cinebox. [www.cinebox .es, consultado el 1/07/14].

Academia de las Artes y las Ciencias Cinematográficas de España. [www.academiadecine.com, consultado el 12/06/14].

ACEC. Área Catalana de Exhibición Cinematográfica [www.cinesacec.es, consultado el 30/05/14].

AEVIDEO. Asociación de Empresas del Vídeo [www.aevideo.es, consultado el 12/05/14].

AISGE. Artistas Intérpretes Sociedad de Gestión [www.aisge.es, consultado el 22/06/14].

Altafilms. [www.altafilms.com, consultado el 13/05/14].

Atresmedia Cine. [www.antena3 .com/antena3-films, consultado el 2/08/14].

Castelao Pictures. [www.filmax.com, consultado el 30/06/14].

Cinesa. [www.cinesa.es, consultado el 16/05/14].

EGEDA. Entidad de Gestión de Derechos de los Productores Audiovisuales [www. egeda.es, consultado el 12/05/14].

El Deseo. [www.fapae.es, consultado el 12/05/14].

Eone. [www.es.eonefilms.com, consultado el 12/07/14].

FAP. Federación para la Protección de la Propiedad Intelectual [www.fap.org.es, consultado el 11/04/14].

FAPAE. Federación de Asociaciones de Productores Audiovisuales de España [www. fapae.es, consultado el 5/05/14].

FECE. Federación de Cines de España [www.fece.com, consultado el 17/06/14].

FEDICINE. Federación de Distribuidores Cinematográficos de España [www.fedicine.com, consultado el 19/06/14].

Filmax. [www.filmax.com, consultado el 9/05/14].

Filmotech. [www.filmotech.com, consultado el 29/08/14].

Golem. [www.golem.es, consultado el 28/7/14].

ICAA. Instituto de la Cinematografía y de las Artes Audiovisuales [www.mcu.es/ cine/index.html, consultado el 1/06/14].

Instituto Cervantes. [www.cervantes.es, consultado el 2/09/14].

Lauren. [www.laurenfilms.es, consultado el 22/05/14].

MPAA. Motion Picture Association of America [www.mpaa.org, consultado el 24/06/14].

Marca España. [www.marcaespana.es, consultado el 28/08/14].

Márgenes. [www.margenes.org, consultado el 10/5/14].

Me siento de cine. [www.mesientodecine.es, consultado el 27/05/14]. 
SGAE. Sociedad General de Autores y Editores [www.sgae.es, consultado el 17/06/14].

Telecinco Cinema. [www.telecinco.es/t5cinema, consultado el 30/08/14].

Tornasol Films. [www.fapae.com, consultado el 25/06/14].

UCC. Unión Cine Ciudad [www.cineciudad .com, consultado el 5/05/14].

Yelmo. [www.yelmocines.es, consultado el 30/08/14]. 